Supporting Information

Mechanistic Investigation of Biomass Oxidation Using

Nickel Oxide Nanoparticles in a $\mathrm{CO}_{2}$-Saturated Electrolyte

\title{
for Paired Electrolysis
}

Seungwoo Choi ${ }^{\dagger}$, Mani Balamurugan ${ }^{\dagger}$, Kang-Gyu Lee ${ }^{\dagger}$, Kang Hee Cho ${ }^{\dagger}$, Sunghak Park ${ }^{\dagger}$, Hongmin $\mathrm{Seo}^{\dagger}$, Ki Tae Nam ${ }^{\dagger}{ }^{*}$

$\dagger$ Department of Materials Science and Engineering, Seoul National University, Seoul 08826, Korea 


\section{Supporting Information}

\section{Experimental methods}

\section{Materials}

$\mathrm{Ni}\left(\mathrm{CH}_{3} \mathrm{COO}\right)_{3}-4 \mathrm{H}_{2} \mathrm{O}$, 5-hydroxymethylfurfural ( $\mathrm{HMF}$, 98\%) were purchased from Acros and used as received without additional purification. $\mathrm{Mn}\left(\mathrm{CH}_{3} \mathrm{COO}\right)_{3}-2 \mathrm{H}_{2} \mathrm{O}(99 \%), \mathrm{Co}\left(\mathrm{CH}_{3} \mathrm{COO}\right)_{3}-$ $4 \mathrm{H}_{2} \mathrm{O}(\geq 98 \%)$, myristic acid $\left(\mathrm{CH}_{3}\left(\mathrm{CH}_{2}\right)_{12} \mathrm{COOH}, \geq 99 \%\right)$, 1-octadecene $\left(\mathrm{CH}_{3}\left(\mathrm{CH}_{2}\right){ }_{15} \mathrm{CH}=\mathrm{CH}_{2}\right.$, 90\%), 1-decanol $\left(\mathrm{CH}_{3}\left(\mathrm{CH}_{2}\right)_{8} \mathrm{CH}_{2} \mathrm{OH}, \geq 98 \%\right)$, 5-hydroxymethyl-2-furancarboxylic acid (HMFCA), 5-formyl-2-furoic acid (FFCA) were purchased from Sigma Aldrich. 2,5diformylfuran (DFF, 98\%) was purchased from Tokyo Chemical Industry. Potassium bicarbonate was purchased form Daejung Chemical \& Metals. All chemicals were used as received without additional purification.

Toray carbon paper (TGP-H-60) and Ni foil ( $0.1 \mathrm{~mm}$ thick, $99.5 \%)$ were purchased from Alfa Aesar, and Fluorine-doped tin oxide glass (FTO-2207A) with sheet resistance of $8 \mathrm{ohms} / \mathrm{sq}$ were manufactured by Wooyang GMS (Korea).

\section{Synthesis of $\mathrm{NiO}, \mathrm{Mn}_{3} \mathrm{O}_{4}, \mathrm{Co}_{3} \mathrm{O}_{4}$ nanoparticles (NPs)}

Three kinds of transition metal oxide NPs ( $\mathrm{NiO}, \mathrm{Mn}_{3} \mathrm{O}_{4}$ and $\mathrm{Co}_{3} \mathrm{O}_{4}$ NPs) were synthesized by a hot injection method by modifying synthetic methods in previous reports. ${ }^{1-3}$ First, two different mixtures were made: one (Solution 1) was $1 \mathrm{mmol}$ of nickel acetate (manganese or cobalt acetate) and $2 \mathrm{mmol}$ of myristic acid in $20 \mathrm{ml}$ of 1-octadecene, and the other (Solution 2) was $3 \mathrm{mmol}$ of 1-decanol in $1 \mathrm{ml}$ of 1 -octadecene. These two mixtures were degassed at $110{ }^{\circ} \mathrm{C}$ for 2 hours with vigorous stirring. After degassing, the Solution 1 was heated up to $295^{\circ} \mathrm{C}$ under argon atmosphere. When the temperature of $295^{\circ} \mathrm{C}$, the Solution 2 was rapidly injected into the Solution 1 to cause the burst nucleation along with super-saturation. The mixture was maintained at $295{ }^{\circ} \mathrm{C}$ for 1 hour under argon atmosphere and then, cooled down to room temperature. 


\section{Electrode preparation}

After the synthesis of the solution with the $\mathrm{NiO}, \mathrm{Mn}_{3} \mathrm{O}_{4}, \mathrm{Co}_{3} \mathrm{O}_{4} \mathrm{NPs}$, the mixture of the $\mathrm{Co}_{3} \mathrm{O}_{4}$ NPs solution, acetone, and toluene in the volume ratio of 1:2:1 were centrifuged 3 times to purify and obtain nanoparticles. The precipitate of nanoparticles was dispersed in hexane. Then, $40 \mathrm{ul}$ of the dispersion was drop-coated on the carbon paper or spin-coated on FTO (for UVVis experiment, spin rate: $2000 \mathrm{rpm}$, holding time: $10 \mathrm{sec}$.), followed by annealing at $300{ }^{\circ} \mathrm{C}$ for 5 hours.

\section{Electrochemical Measurements}

The general electrochemical measurements were conducted in a three-electrode system where Pt foil and $\mathrm{Ag} / \mathrm{AgCl}$ electrode were used as a counter electrode and a reference electrode, respectively. All potentials were controlled against a $\mathrm{Ag} / \mathrm{AgCl}$ reference electrode (3.0 M

$\mathrm{NaCl}, \mathrm{BASi}$ ) utilizing a potentiostat (BioLogic Science Instruments). The applied potential was converted to the relative hydrogen electrode (RHE) using the following equation, E (vs. RHE) $=\mathrm{E}(\mathrm{vs} . \mathrm{Ag} / \mathrm{AgCl})+0.197 \mathrm{~V}+0.0591 * \mathrm{pH}$. In the case of in situ UV-Vis experiments, the normal hydrogen electrode (NHE) was calculated by the following equation, $\mathrm{E}$ (vs. NHE) = E (vs. $\mathrm{Ag} / \mathrm{AgCl})+0.197 \mathrm{~V}$. To avoid any effects from the counter compartment, H-cell with a Nafion ${ }^{\circledR}$ N-117 membrane $(0.180 \mathrm{~mm}$ thick, Alfa Aesar) was used as a separator where the volume of anolyte and catholyte was $5 \mathrm{ml}$. The geometric area of the working electrode was $0.5 \mathrm{~cm}^{2}$ and all the experiments were conducted with stirring Also, applied potentials were compensated by solution resistivity measured by the electrochemical impedance spectroscopic technique in the potentiostat. Simultaneous conversion of $\mathrm{HMF}$ and $\mathrm{CO}_{2}$ was carried out in a two-electrode system which was designed by the previously reported $\mathrm{CO}_{2}$ reduction system.

\section{Product analysis and calculation method}

To calculate current efficiencies of $\mathrm{NiO}, \mathrm{Mn}_{3} \mathrm{O}_{4}$ and $\mathrm{Co}_{3} \mathrm{O}_{4} \mathrm{NPs}$ for $\mathrm{HMF}$ oxidation as shown in Figure 1b, bulk electrolysis was conducted at current densities of 1, 5, and $10 \mathrm{~mA} \mathrm{~cm}^{-2}$ up to $2.895 \mathrm{C}$ of charge, which is $10 \%$ of the total theoretical columbic charge required for the conversion of $10 \mathrm{mM} \mathrm{HMF}$ in $5 \mathrm{~mL}$ solution. To evaluate HMF oxidation products, chronoamperometry (CA) was performed by applying five different potentials $(1.50,1.55,1.60$, 1.65, and $1.70 \mathrm{~V}$ vs RHE) and passing $28.95 \mathrm{C}$ which is required to fully oxidize HMF to 
FDCA. The reaction time for HMF oxidation was about 14, 8, 4, 2 and 2 hours at each potential. The oxidation products were quantified at each potential by analyzing the electrolyte using ${ }^{1} \mathrm{H}$ nuclear magnetic resonance (NMR) spectroscopy. The yield (\%) and the Faradaic efficiency (\%) of the HMF oxidation products were calculated based on Equation 1 and 2, in which $F$ is the Faraday constant $\left(96485 \mathrm{C} \mathrm{mol}^{-1}\right)$ and $n$ is the number of electrons required for the oxidation of HMF to formed product. ${ }^{4-6}$ In detail, 2 electrons are required for the production of HMFCA and DFF $\left(\mathrm{HMF}+2 \mathrm{OH}^{-} \rightarrow \mathrm{HMFCA}+2 \mathrm{H}_{2} \mathrm{O}+2 \mathrm{e}^{-}, \mathrm{HMF}+2 \mathrm{OH}^{-} \rightarrow \mathrm{DFF}+2 \mathrm{H}_{2} \mathrm{O}+2 \mathrm{e}^{-}\right)$. In addition, 4 and 6 electrons are needed for the formation of FFCA and FDCA $\left(\mathrm{HMF}+4 \mathrm{OH}^{-} \rightarrow\right.$ $\mathrm{FFCA}+4 \mathrm{H}_{2} \mathrm{O}+4 \mathrm{e}^{-}, \mathrm{HMF}+6 \mathrm{OH}^{-} \rightarrow$ FDCA $\left.+6 \mathrm{H}_{2} \mathrm{O}+6 \mathrm{e}^{-}\right)$, respectively.

Yield of product $(\%)=\frac{\text { mol of product formed }}{\text { mol of initial HMF }} \times 100$

Faradaic efficiency $(\%)=\frac{\text { mol of product formed }}{\text { total charge passed } /(F \times n)} \times 100$

The yield represents the proportion of the formed products from initial HMF molecules, meanwhile the Faradaic efficiency (FE) exhibits the efficiency with which electrons (charge) are transferred in each electrochemical reaction.

\section{Transmission/Scanning electron microscopy (TEM/SEM)}

The morphology of NiO NPs was characterized by high-resolution transmission electron microscopy (HRTEM) images using a high-resolution transmission electron microscope (JEM$2100 \mathrm{~F}, \mathrm{JEOL})$ at an acceleration voltage of $200 \mathrm{kV}$. A field-emission scanning electron microscope (SUPRA 55VP, Carl Zeiss, Germany) images were taken under the acceleration voltage of $2.00 \mathrm{kV}$.

\section{X-ray Diffraction (XRD)}

NiO NPs powders were collected by the purification and annealing processes. The XRD measurement was conducted by X-ray diffractometer (D8-Advance, Bruker Miller Co.) with a $\mathrm{Cu}$ Ka radiation ( $\lambda=1.5406 \AA$ ). The XRD pattern of Ni NPs was measured from $20^{\circ}$ to $70^{\circ}$ with an increment step of $0.02^{\circ}$.

\section{X-ray Photoelectron Spectroscopy (XPS)}

XPS spectrum of NiO NPs were conducted by photoelectron spectrometer (AXIS-HSi, Kratos) 
with a pass energy of $40 \mathrm{eV}$ and step size of $50 \mathrm{meV}$. The obtained XPS spectrum were calibrated with $\mathrm{C} 1 \mathrm{~s}$ peak $(284.8 \mathrm{eV})$ as the standard reference.

\section{Tafel slope caculation}

The Tafel slope (b) can be calculated from the current density $(j)$-potential (E) relationship (Equation 3), where $j_{0}, \alpha, \mathrm{F}, \mathrm{E}^{0}$ and $\mathrm{b}$ are the exchange current density, the charge transfer coefficient, the Faraday constant, the thermodynamic equilibrium potential and the Tafel slope, respectively. This also can be expressed as Equation 4, being inversely related to the transfer coefficient. $^{7,8}$

$j=j_{0} \exp \left(\frac{\alpha F\left(E-E^{0}\right)}{R T}\right)$

$\mathrm{b}=\frac{\partial \mathrm{E}}{\partial \log j}=\frac{2.303 R T}{\alpha F}$

\section{${ }^{1}$ H NMR analysis}

The concentration of reactant HMF and produced DFF, HMFCA, FFCA, FDCA were analyzed by a $600 \mathrm{MHz}$ nuclear magnetic resonance (NMR) spectrometer (Avance 600, Bruker). The anolyte $(1 \mathrm{~mL})$ containing the liquid product was mixed with the $\mathrm{D}_{2} \mathrm{O}$ solution $(50 \mu \mathrm{L})$ of 10 $\mathrm{mM}$ dimethyl sulfoxide (DMSO) as internal standards. The one-dimensional $1 \mathrm{H} \mathrm{NMR}$ spectrum was measured with solvent suppression to cut the water peak down.

\section{In situ UV-Vis spectroscopy}

In situ UV-Vis absorption spectra were obtained in diffuse transmission mode using a UV-Vis spectrometer (UV-2550, Shimazu) equipped with a multi-purpose large-sample compartment and a built-in integrating sphere (MPC-2200, Shimadzu). For in-situ acquisition of spectra, an electrode mounted in an electrochemical cell was placed in front of the integrating sphere to collect diffused transmission light.

Spectral changes of the NiO NPs electrode induced by the catalytic reaction were observed between $0.8 \mathrm{~V}$ and $1.3 \mathrm{~V}$ vs the normal hydrogen electrode (NHE) in $0.1 \mathrm{~V}$ increments. A fluorine-doped tin oxide (FTO) substrate was used as an electrode substrate instead of the carbon paper substrate to avoid light absorption and scattering by the carbon paper. Additionally, differential spectra were obtained at each potential by subtraction of the spectra 
obtained at open circuit potential (OCP) to estimate the nickel species formed on the surface of the NiO NPs (Figure $4 b$ and Figure 4c).

\section{References}

(1) Jin, K.; Chu, A.; Park, J.; Jeong, D.; Jerng, S. E.; Sim, U.; Jeong, H.-Y.; Lee, C. W.; Park, Y.-S.; Yang, K. D. et al., Partially oxidized sub-10 $\mathrm{nm} \mathrm{MnO}$ nanocrystals with high activity for water oxidation catalysis. Sci. Rep. 2015, 5, 10279.

(2) Jin, K.; Seo, H.; Hayashi, T.; Balamurugan, M.; Jeong, D.; Go, Y. K.; Hong, J. S.; Cho, K. H.; Kakizaki, H.; Bonnet-Mercier, N. et al., Mechanistic investigation of water oxidation catalyzed by uniform, assembled MnO nanoparticles. J. Am. Chem. Soc. 2017, 139 (6), 2277-2285.

(3) Ha, H.; Jin, K.; Park, S.; Lee, K.-G.; Cho, K. H.; Seo, H.; Ahn, H.-Y.; Lee, Y. H.; Nam, K. T., Highly selective active chlorine generation electrocatalyzed by $\mathrm{Co}_{3} \mathrm{O}_{4}$ nanoparticles: Mechanistic investigation through in situ electrokinetic and spectroscopic analyses. J. Phys. Chem. Lett. 2019, 10 (6), 1226-1233.

(4) Cha, H. G.; Choi, K.-S., Combined biomass valorization and hydrogen production in a photoelectrochemical cell. Nat. Chem. 2015, 7, 328-333.

(5) Kwon, Y.; Schouten, K. J. P.; van der Waal, J. C.; de Jong, E.; Koper, M. T., Electrocatalytic conversion of furanic compounds. ACS Catal. 2016, 6 (10), 6704-6717.

(6) You, B.; Liu, X.; Jiang, N.; Sun, Y., A general strategy for decoupled hydrogen production from water splitting by integrating oxidative biomass valorization. J. Am. Chem. Soc. 2016, 138 (41), 1363913646.

(7) Shinagawa, T.; Garcia-Esparza, A. T.; Takanabe, K., Insight on Tafel slopes from a microkinetic analysis of aqueous electrocatalysis for energy conversion. Sci. Rep. 2015, 5, 13801-13801.

(8) Suen, N.-T.; Hung, S.-F.; Quan, Q.; Zhang, N.; Xu, Y.-J.; Chen, H. M., Electrocatalysis for the oxygen evolution reaction: Recent development and future perspectives. Chem. Soc. Rev. 2017, 46 (2), 337-365. 

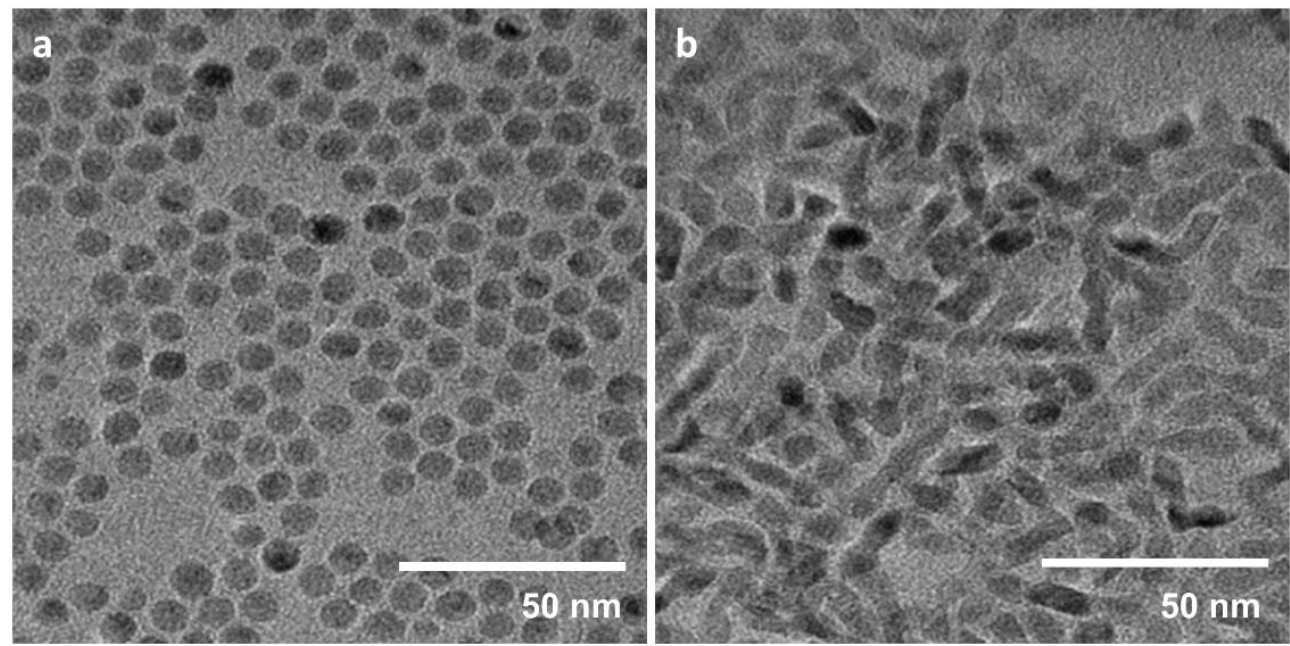

\section{Figure S1}

HRTEM images of synthesized (a) $\mathrm{Mn}_{3} \mathrm{O}_{4}$ nanoparticles and (b) $\mathrm{Co}_{3} \mathrm{O}_{4}$ nanoparticles
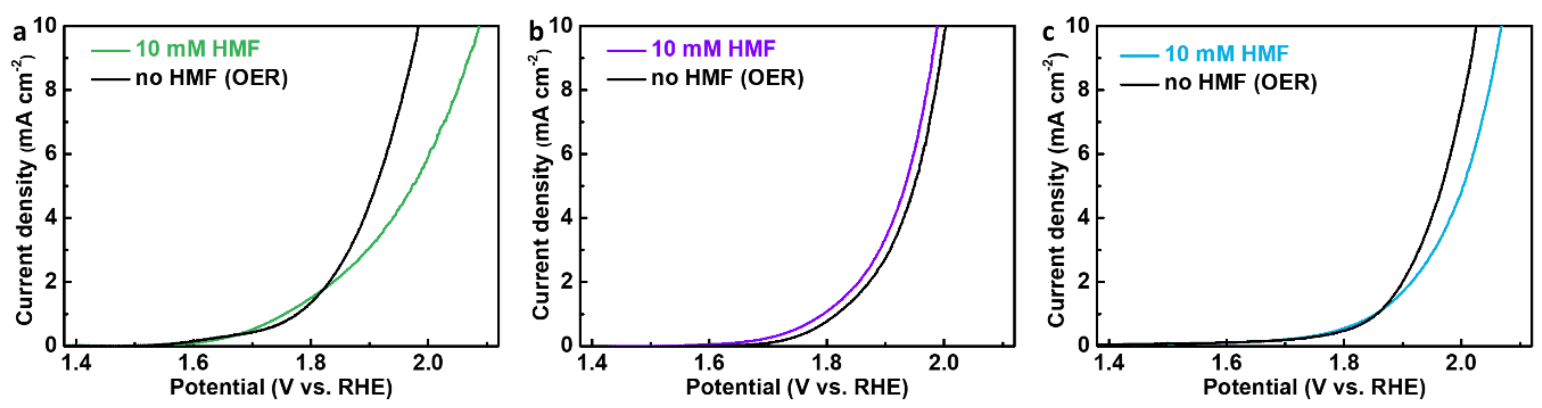

\section{Figure S2}

Comparison of the LSVs of various nickel oxide-based catalysts. Each catalytic activity for HMF oxidation reaction was tested with and without addition of $10 \mathrm{mM} \mathrm{HMF}$. The LSVs of (a) electrodeposited nickel oxide (b) oxidized $\mathrm{Ni}$ foil (c) the commercial microsized $\mathrm{NiO}$ 


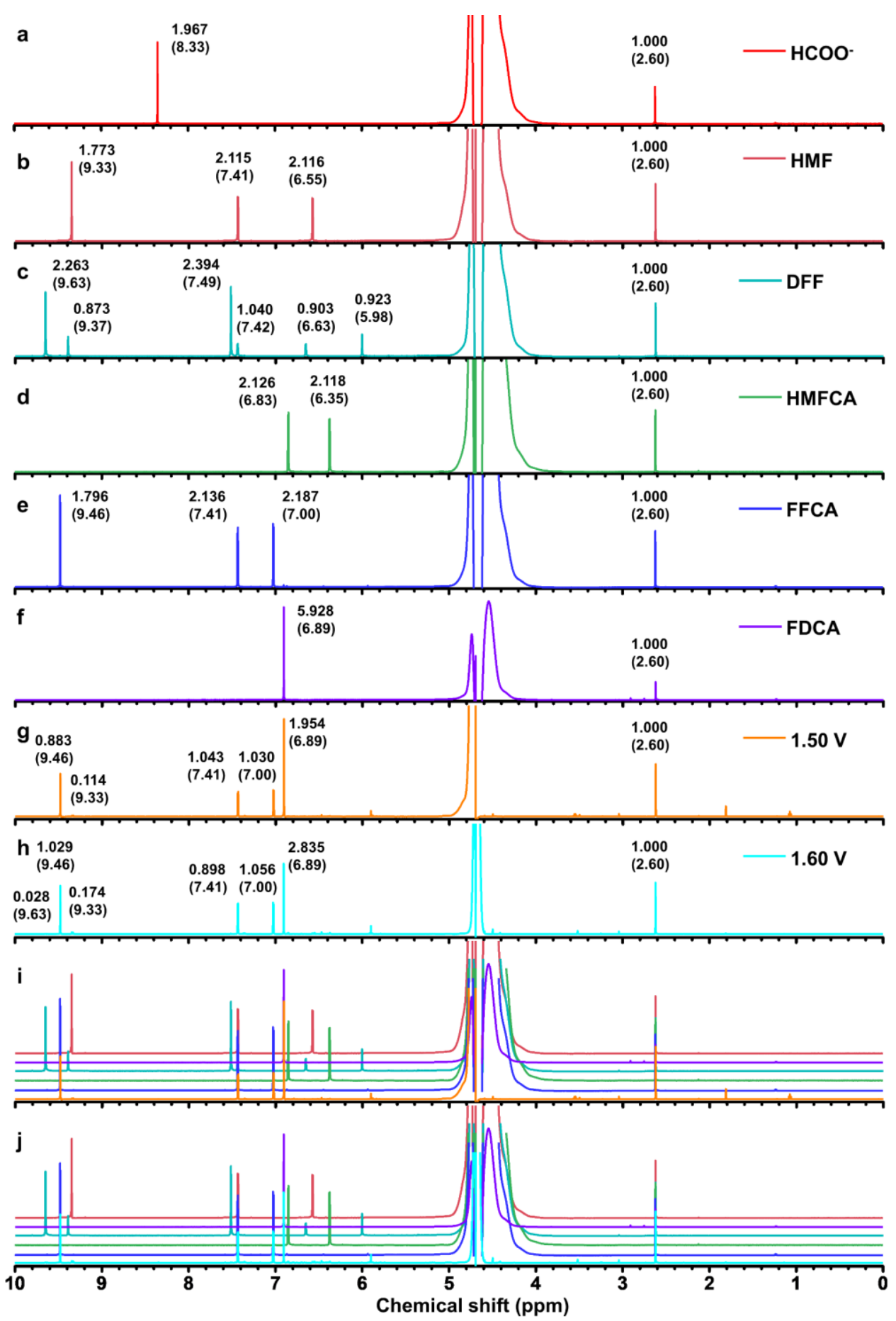

\section{Figure S3}

${ }^{1} \mathrm{H}$ NMR spectra of the $10 \mathrm{mM}$ standard solutions (a) $\mathrm{HCOO}^{-}$(b) HMF (c) DFF (d) HMFCA (e) FFCA (f) FDCA and the resultant solutions after bulk electrolysis at (g) $1.50 \mathrm{~V}$ (h) $1.60 \mathrm{~V}$ vs RHE. The overlapping spectra of the solutions after bulk electrolysis at (i) $1.50 \mathrm{~V}$ (j) $1.60 \mathrm{~V}$ vs RHE with HMF, FDCA, DFF, HMFCA and FFCA. The peak areas (positions) were denoted on the top of each peak. 


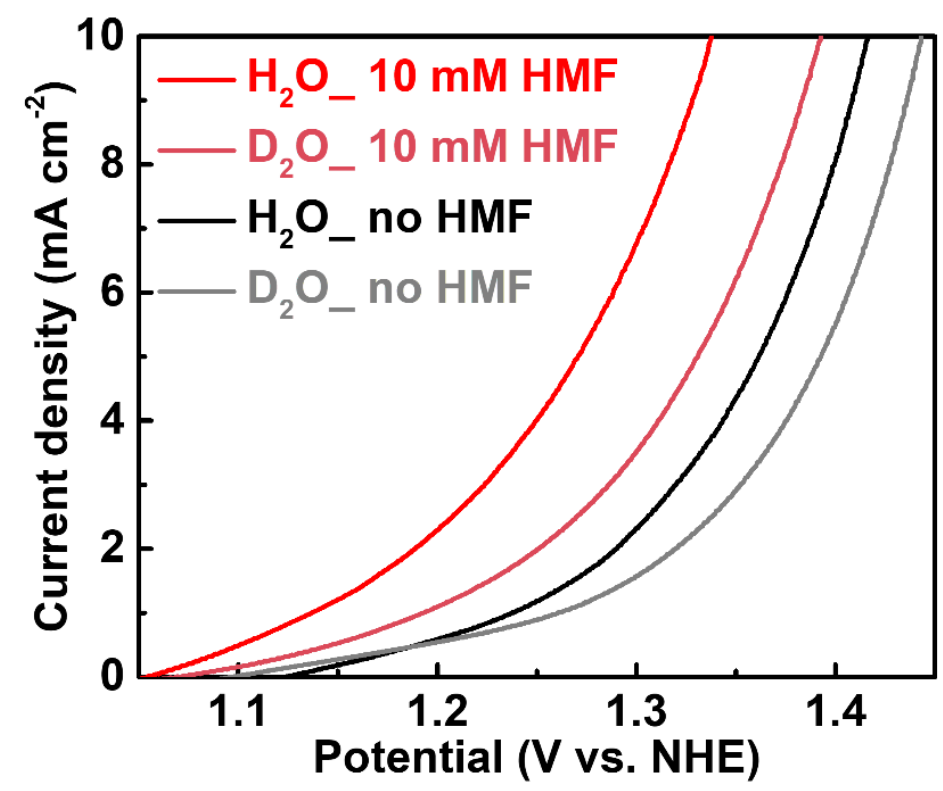

Figure S4

The proton dependence of the catalytic activity for the HMF oxidation on NiO NPs under nearneutral condition with $\mathrm{D}_{2} \mathrm{O}$ solvent.

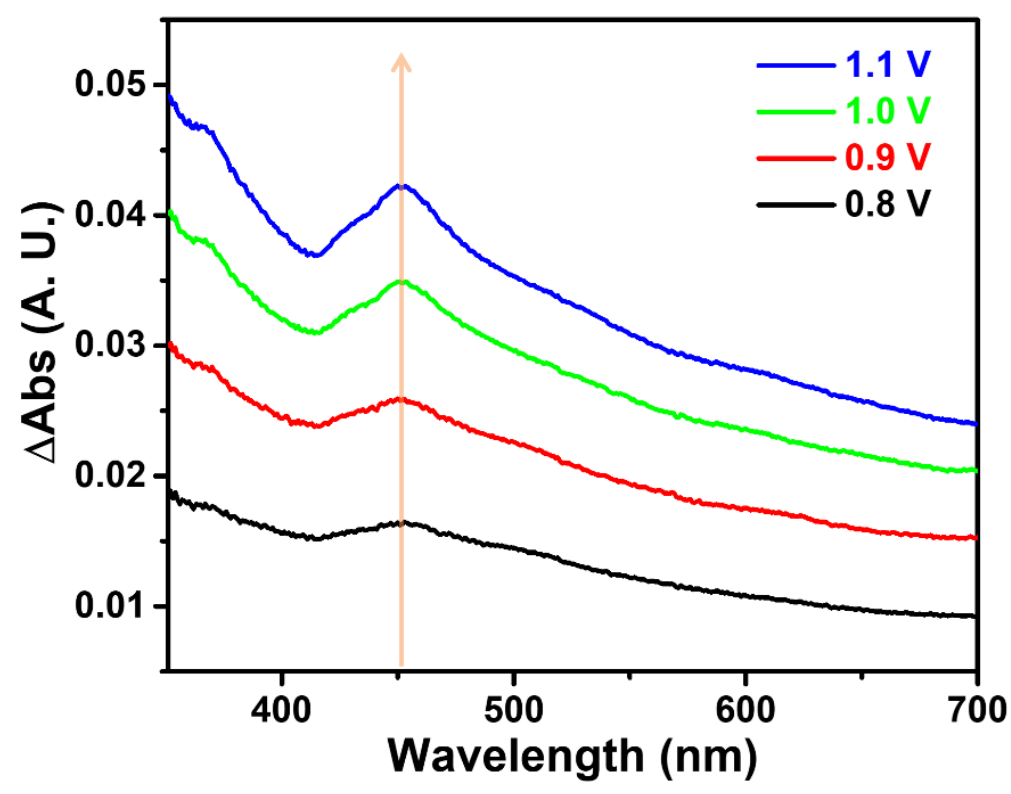

Figure S5

In situ UV-Vis difference spectrum of NiO NPs at increasing potentials $(0.8,0.9,1.0,1.1 \mathrm{~V}$ vs NHE) in the presence of $10 \mathrm{mM}$ HMF. Two absorption band in the region of and $453 \mathrm{~nm}$ increased along with the enhancement of applied potential (Figure 4c). 

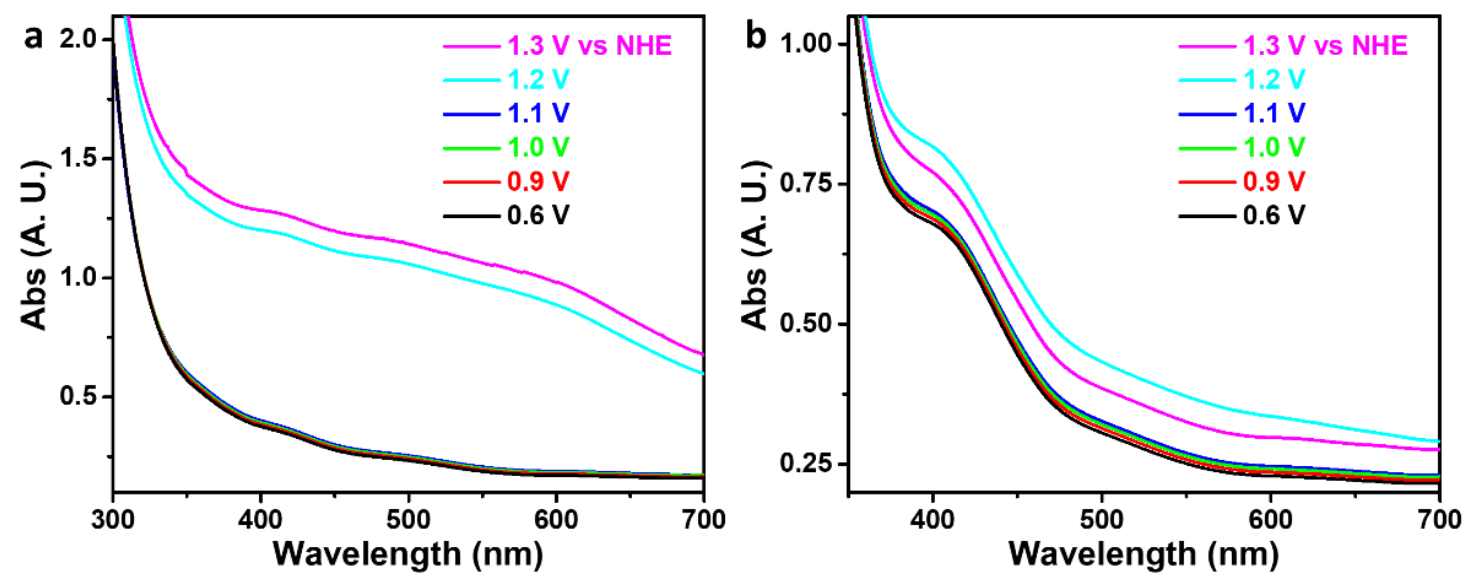

\section{Figure S6}

Diffuse transmission UV-Vis absorption spectra of NiO NPs film at increasing potentials (a) in the absence of $10 \mathrm{mM}$ HMF and (b) in the presence of $10 \mathrm{mM}$ HMF. The spectrum measured at $0.6 \mathrm{~V}$ vs NHE was used as a reference spectrum to display changes in the UV-Vis spectrum (Figure $4 \mathrm{~b}$ and $\mathrm{c}$ ).
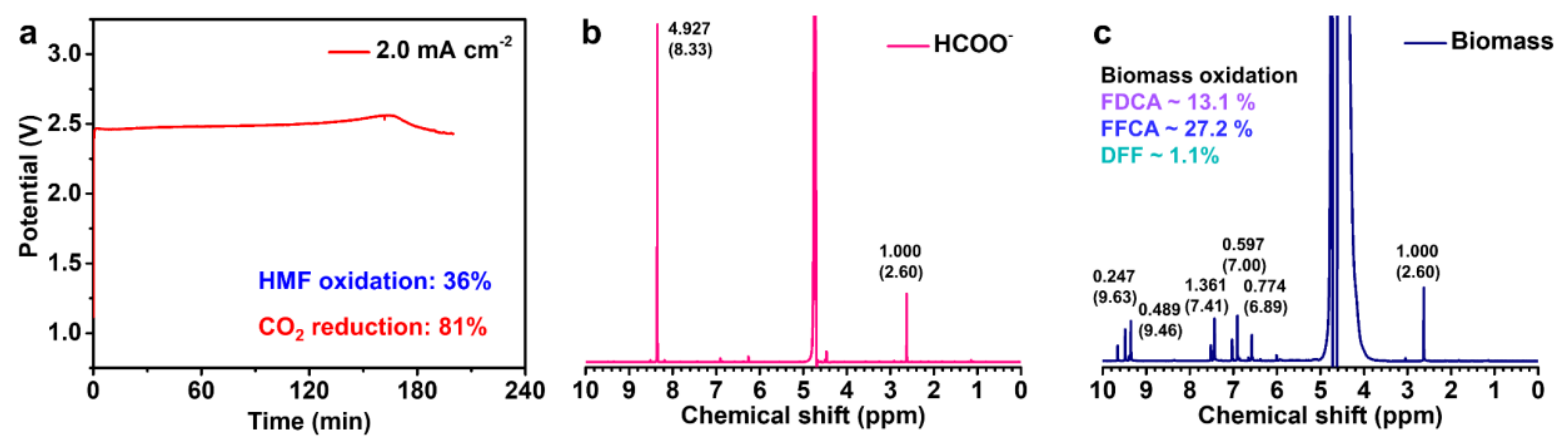

\section{Figure S7}

Bulk electrolysis was conducted with a 2-electrode system in $\mathrm{CO}_{2}$-saturated $0.5 \mathrm{M} \mathrm{KHCO}_{3}$. (a) A $2.5 \mathrm{~V}$ cell voltage was achieved at current density of $2 \mathrm{~mA} \mathrm{~cm}^{-2}$, with $36 \% \mathrm{FE}$ for HMF oxidation and $81 \% \mathrm{FE}$ for $\mathrm{CO}_{2}$ reduction to formate $\left(\mathrm{HCOO}^{-}\right) .{ }^{1} \mathrm{H}$ NMR spectra of the resultant solutions in (b) cathodic compartment and (c) anodic compartment after bulk electrolysis. The peak areas (positions) were denoted on the top of each peak. 